\title{
Noninvasive imaging in the diagnosis of acute viral myocarditis
}

\author{
Michael Jeserich
}

Published online: 18 March 2010

(c) The Author(s) 2010. This article is published with open access at Springerlink.com

\section{Authors' reply}

We hereby respond to the comments of M. Gutberlet and H. Thiele to our review [1]. The first comment pertains to the assessment of pericardial effusion. A steady-state-free precession sequence (SSFP) is the basis of every myocardial examination and therefore should be used in every cardiac patient when evaluating left ventricular function and dimensions, 2, 3 and 4-chamber long-axis views, and 3-D short-axis volume, hence in every patient with pericardial effusion. T1- and T2-weighted images are additional sequences, useful in this patient cohort.

The next topic addresses simple "eye-balling" in myocarditis. It was our intention to explain to the reader that a profound assessment of a proposed myocardial edema by modern sequences, such as a "STIR" sequence, a special T2-weighted image, must be followed by a thorough analysis. As stated in our review, the ratio of global myocardial signal intensity/muscle signal (global T2 ratio) intensity should be determined. This technique was introduced by Friedrich et al. [2] and used by Gutberlet et al. [3] and our group [4]. We discussed this technique and the published papers in detail in the "T2-weighted images" section, and, thus, do not understand the comments of Gutblerlet et al. In Fig. 1 of our review, that patient's global T2 ratio was profoundly enhanced, indicating myocardial edema. This was an example of globally diffuse edema, not regional edema, as stated by M. Gutberlet and $\mathrm{H}$. Thiele. Gutberlet and Thiel's image 1 depicts a regional

M. Jeserich $(\square)$

Department of Cardiology and Angiology, Albert Ludwig University of Freiburg, Freiburg, Germany e-mail: info@Praxis-Jeserich.de edema, another well-known possibility in myocarditis, but a distinct feature.

Images acquired late (10-20 min) after application of paramagnetic contrast agents provide a sensitive tool for detecting myocardial fibrosis or necrosis, which is distinguished by bright late-enhancement regions due to the increased volume of distribution and delayed washout of the contrast agent from affected myocardium late gadolinium enhancement (LGE) has been thoroughly investigated in myocarditis, as mentioned in our review. Gutberlet et al. raise concern that field inhomogeneities may have occurred in Fig. 5, leading to ineffective "nulling". That problem is familiar to cardiovascular magnetic resonance users. In this case, we used different inversion times to rule out that possibility. Moreover, this patient presented a diffuse hypocontractility of the septum, and frequent premature ventricular beats. Furthermore, the patient revealed no enhancement of the lateral or anterior wall, which would have been the case had field inhomogeneities occurred. In addition, the diffuse enhancement of the septum or lateral wall is a well-documented possibility in non-ischemic diseases and was recently reported by Rolf et al. [5] for example. The findings typical of chronic myocarditis are much more discreet. Often, only one or a few foci are visible. Therefore, we included Fig. 4.

Finally, we discussed the work of Gutblerlet et al. in detail in our review: "Assomull et al. [6] and Gutberlet et al. [3] used novel T2-weighted sequences as well, demonstrating good results in detecting myocarditis (section "T2-weighted images") and Gutberlet et al. [3] also compared T1- and T2-weighted images for diagnosing myocarditis. Their diagnostic accuracy was 72 and 68\%, respectively. Thus, the concordance between novel magnetic resonance modalities and biopsy results is acceptable, but further research remains necessary" (under the section 
entitled "Accuracy of cardiovascular magnetic resonance in relation to biopsy-confirmed cases"). In the section "Late-enhancement technique" we wrote: "In a study Gutberlet et al. analyzed 83 patients with chronic myocarditis. They found a lower sensitivity and accuracy of T1- and T2-weighted images. Their specificity was acceptable with $80 \%$ ". Thus, the "lower sensitivity and accuracy" we mention refers to the fact that the specificity was higher.

In summary, we regret that, for the reasons explained in detail above, we must disagree with every comment made by Gutberlet et al. regarding the cardiovascular part of our manuscript.

Open Access This article is distributed under the terms of the Creative Commons Attribution Noncommercial License which permits any noncommercial use, distribution, and reproduction in any medium, provided the original author(s) and source are credited.

\section{References}

1. Jeserich M, Konstantinidis S, Pavlik G, Bode C, Geibel A (2009) Noninvasive imaging in the diagnosis of acute viral myocarditis. Clin Res Cardiol 98:753-763
2. Friedrich MG, Strohm O, Schulz-Menger J, Marciniak H, Luft FC, Dietz R (1998) Contrast media-enhanced magnetic resonance imaging visualizes myocardial changes in the course of viral myocarditis. Circulation 97:1802-1809

3. Gutberlet M, Spors B, Thoma T, Bertram H, Denecke T, Felix R, Noutsias M, Schultheiss HP, Kühl U (2008) Suspected chronic myocarditis at cardiac MR: diagnostic accuracy and association with immunohistologically detected inflammation and viral persistence. Radiology 246:401-409

4. Jeserich M, Olschewski M, Bley T, Merkle N, Kirchberger J, Pavlik G, Bode C, Geibel A (2009) Cardiac envolement after respiratory tract viral infection-detection by cardiac magnetic resonance. J Comput Assist Tomogr 33:15-19

5. Rolf A, Nef HM, Ilmann HM, Ch Troidl, Voss S, Conradi G, Rixe J, Steiger H, Beiring K, Hamm CW, Th Dill (2009) Immunohistological basis of the late gadolinium enhancement phenomenon in tako-tsubo cardiomyopathy. Eur Heart J 30:1635-1642

6. Assomull RG, Lyne JC, Keenan N, Gulati A, Bunce NH, Davies SW, Pennell DJ, Prasad SK (2007) The role of cardiovascular magnetic resonance in patients presenting with chest pain, raised troponin and unobstructed coronary arteries. Eur Heart J 28:12421249 